\title{
Origenes' Johanneskommentar Buch I-V
}

\author{
Hrsg., übers. u. komm. v. Hans G. Thümmel
}

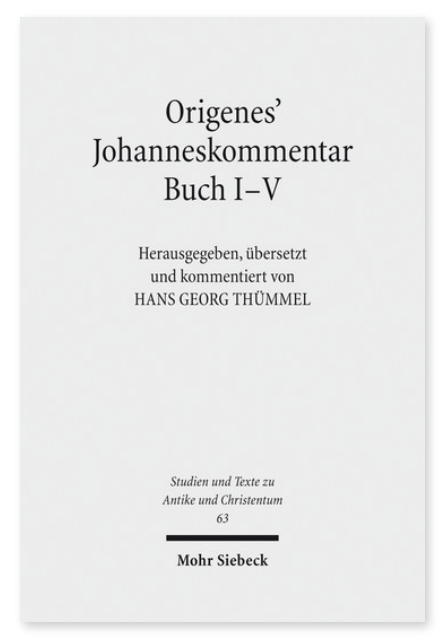

2011. XV, 276 Seiten. STAC 63

ISBN 978-3-16-151765-5

DOI 10.1628/978-3-16-151765-5

eBook PDF $69,00 €$

ISBN 978-3-16-150584-3

fadengeheftete Broschur $69,00 €$
Origenes hat über einen längeren Zeitraum hinweg Auslegungen zum Johannesevangelium an seinen Mäzen Ambrosius geschrieben. Von dem Werk ist ein knappes Drittel erhalten, wovon Hans G. Thümmel Buch 1 und 2 sowie die erhaltenen Fragmente von Buch 4 und 5 behandelt. Sie beziehen sich auf den Prolog des Johannesevangeliums. Die Publikation verbessert vor allem anhand der Korrekturlisten der älteren Rezensionen den Text und bietet eine Übersetzung. Weitere Klärungen gibt ein Kommentar.Grundlegend für die Ausführungen des Origenes über den lo 1,1 genannten Logos ist die Vorstellung des Schöpfungsmittlers, der gleichermaßen die Zusammenfassung der Schöpfung darstellt. Origenes verbindet inn mit der Sophia in gleicher Funktion. Das bedeutet aber nicht, daß Origenes abstrakte Metaphysik betreibt. Ihm geht es um den Menschen in seinem erlösungsbedürftigen Zustand, und alles ist darauf angelegt, diesen Zustand zu erklären und dann zu zeigen, wie der Mensch ihn überwinden kann. Origenes entwickelt seine Vorstellungen von der Schöpfung als Folge eines Abfalls und vom Heil als Rückkehr zu Gott. Er bemüht sich, für jede Aussage die exegetische Grundlage darzulegen, wofür er besonders auf Paulus rekurriert. Er ist überzeugt, in allem, was er sagt, das göttliche Wort auszulegen. So begegnen sich bei Origenes die feste Überzeugung, daß Gott in dem verbal inspirierten Text spricht, der deshalb auch in grammatischen Feinheiten ernst genommen werden muß, und eine feste Vorstellung davon, wie sich das Drama von Gott und Welt, Abfall und Rückkehr vollzogen hat und vollzieht. Beides steht in einer gewissen Spannung zueinander, erklärt sich aber letztlich gegenseitig.

Hans Georg Thümmel Geboren 1932; Professor emeritus für Kirchengeschichte, Christl. Archäologie und Geschichte der christlichen Kunst.

Jetzt bestellen:

https://mohrsiebeck.com/buch/origenes-johanneskommentar-buch-i-v-9783161517655?no_cache=1

order@mohrsiebeck.com

Telefon: +49 (0)7071-923-17

Telefax: +49 (0)7071-51104 